\title{
Characterization of the disturbed zone in a large rock excavation for the Three Gorges Project
}

\author{
J.H. Deng, C.F. Lee, and X.R. Ge
}

\begin{abstract}
Excavation in a rock mass leads to the perturbation of the stress regime, often creating a stress-relieved, locally weakened zone known as the disturbed zone. This paper presents the results of in situ studies that were carried out both in the central rock barrier (or separation block) between the shiplift and the temporary shiplock and in the northern slope of the permanent shiplock of the Three Gorges Project. The vertical extent of the disturbed zone was determined jointly by cross-hole seismic wave penetration testing and borehole elastic modulus testing, and the horizontal extent was assessed by monitoring and evaluating the deformation characteristics. Compared with the undisturbed rock mass, the $P$-wave velocity of the disturbed zone was reduced by $34-38 \%$ and the borehole elastic modulus by $12-31 \%$. The reductions were caused by the opening of primary structural planes or the extension of apertures due to local sliding along the structural planes. In the disturbed zone, no newly formed fractured planes were found. The observed disturbed zone was compared with the tensile stress zones and the shear-damaged zones calculated by the finite element method. A rock reinforcement scheme was recommended and implemented.
\end{abstract}

Key words: disturbed zone, mechanical properties, brittle rock mass, excavation, finite element method, reinforcement.

Résumé : Une excavation dans une masse rocheuse produit une perturbation du régime des contraintes, créant souvent une zone de relâchement de contraintes localement affaiblie connue comme la zone remaniée. Cet article présente les résultats d'études qui ont été réalisées dans la barrière rocheuse centrale (ou le bloc de séparation) entre l'élévateur à bateau et l'écluse temporaire, de même que dans la pente nord de l'écluse permanente du projet des Trois Gorges. L'étendue verticale de la zone remaniée a été déterminée par l'essai de pénétration d’ondes sismiques crosshole et l'essai de module élastique en forage, alors que l'étendue verticale a été estimée en mesurant et évaluant les caractéristiques de déformation. On a trouvé que par rapport à la masse rocheuse non remaniée, le vitesse de l'onde $P$ de la zone remaniée a été réduite de quelque $34 \%$ à $38 \%$, et le module élastique mesuré en forage, de $12 \%$ à $31 \%$. Les réductions ont été causées par l'ouverture des plans structuraux primaires ou par l'extension de trouées dues au glissement local le long de plan structuraux. Dans la zone remaniée, on n'a pas trouvé de plans de fracture nouvellement formés. La zone remaniée a été comparée avec les zones de contrainte de traction et les zones endommagées par le cisaillement calculées par la méthode d'éléments finis. Un plan de renforcement de la roche a été recommandé et exécuté.

Mots clés : zone remaniée, propriétés mécaniques, masse rocheuse fragile, excavation, méthode d'éléments finis, renforcement.

[Traduit par la Rédaction]

\section{Introduction}

The navigation structures of the Three Gorges Project are composed of the permanent shiplock, the shiplift, and the temporary shiplock, all located on the left bank of the Yangtze River (Fig. 1). The permanent shiplock comprises a twoway, five-step system, with each chamber measuring $280 \mathrm{~m} \times$ $34 \mathrm{~m} \times 5 \mathrm{~m}$ (length $\times$ width $\times$ minimum water depth). The shiplift is designed to vertically hoist a $120 \mathrm{~m} \times 18 \mathrm{~m} \times$ $3.5 \mathrm{~m}$ ship container. The temporary shiplock is planned for

Received November 9, 1999. Accepted June 21, 2000.

Published on the NRC Research Press Web site on

February 14, 2001.

J.H. Deng and X.R. Ge. Institute of Rock and Soil Mechanics, The Chinese Academy of Sciences, Wuhan 430071, China.

C.F. Lee. Department of Civil Engineering, University of Hong Kong, Hong Kong, China. use during the construction period with an effective chamber size of $240 \mathrm{~m} \times 24 \mathrm{~m} \times 4 \mathrm{~m}$.

These navigation structures have been constructed by deep excavation into the bedrock to maximum depths of 173.5 , 140 , and $86 \mathrm{~m}$ for the permanent shiplock, shiplift, and temporary shiplock, respectively. The dominant rock type is plagioclase granite, which is divided into four zones according to the degree of weathering, viz., completely weathered (IV), highly weathered (III), moderately weathered (II), and slightly weathered and fresh (I). Benches were left during excavation and were usually $15 \mathrm{~m}$ high and $5 \mathrm{~m}$ wide with a slope of 1 (vertical) to 1 (horizontal) for the completely weathered and highly weathered zones, 1 to 0.5 for the moderately weathered zone, and 1 to 0.3 or vertical for the slightly weathered and fresh zone. The vertical slopes were excavated to create walls of chambers for both the shiplocks and the shiplift. The height of the vertical slope was 50$70 \mathrm{~m}$ for the permanent shiplock, $29 \mathrm{~m}$ for the temporary shiplock, and 34-51 m for the shiplift (Figs. 2, 3). A central 
Fig. 1. Layout of the navigation structures of the Three Gorges Project.

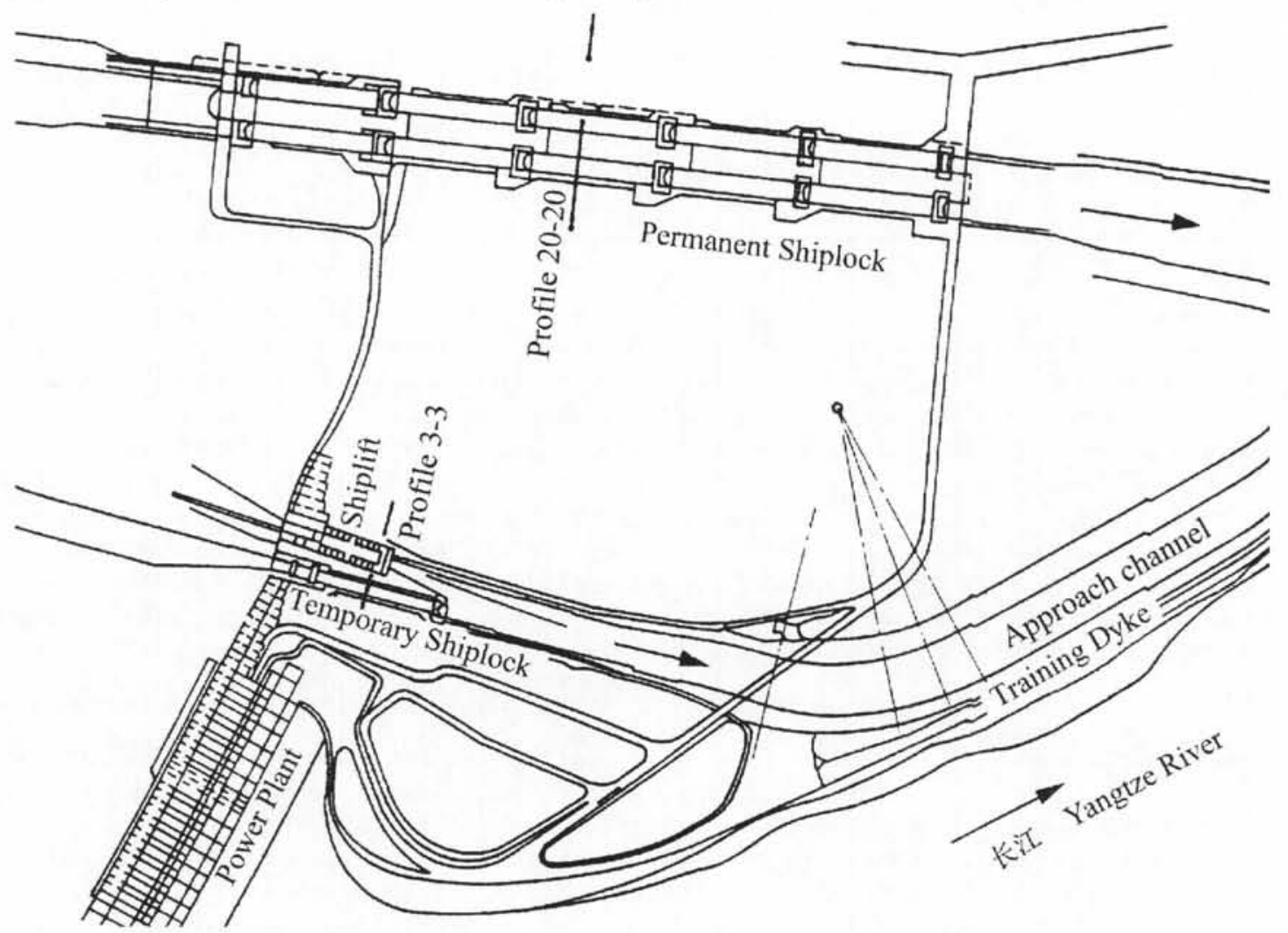

Fig. 2. Investigation profile 3-3 of the shiplift and the temporary shiplock slope.

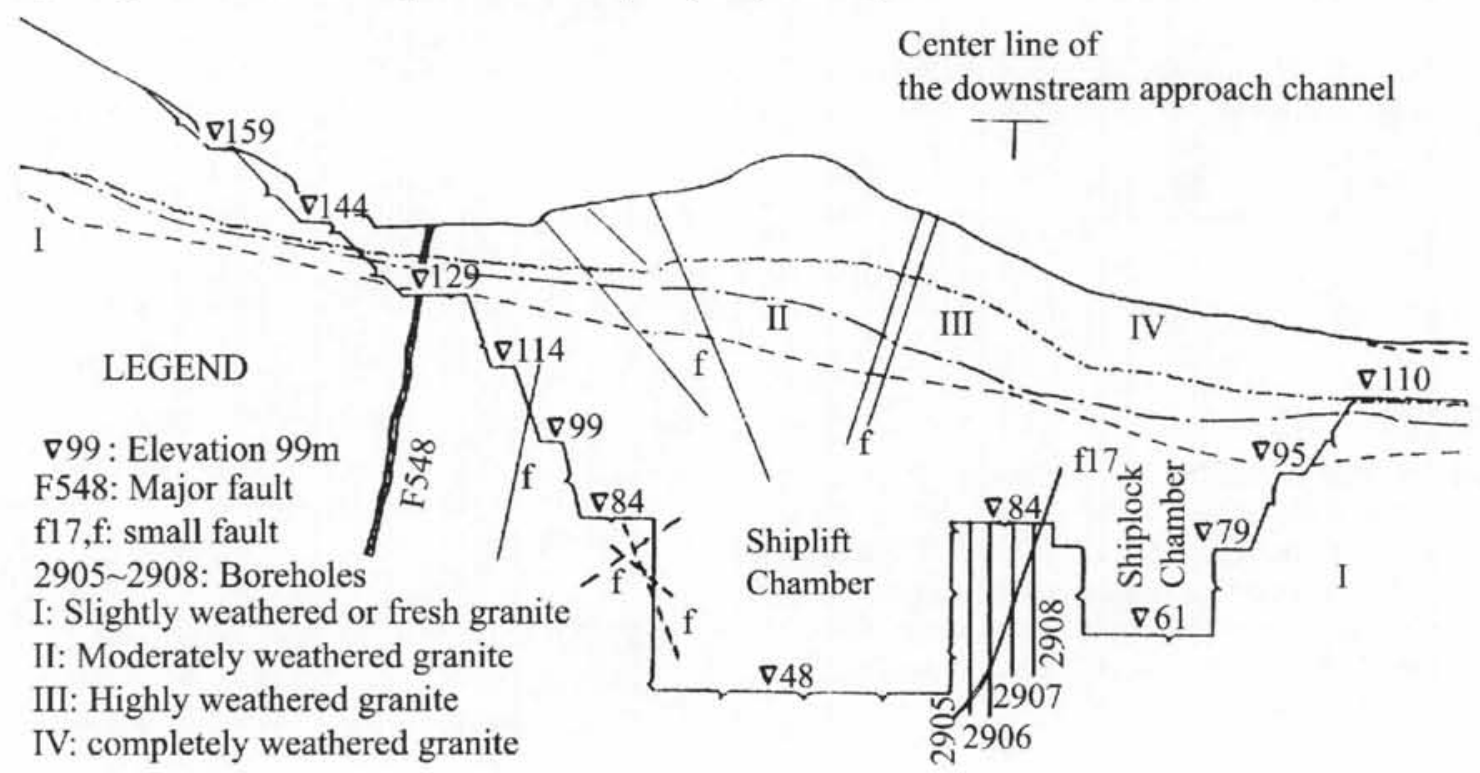

rock barrier (or separation block) 55-57 m wide and 50-70 m high was kept between the two channels of the permanent shiplock (Fig. 3). Another central rock barrier measuring $16-34 \mathrm{~m}$ wide and $23-36 \mathrm{~m}$ high was also left between the shiplift chamber and the temporary shiplock (Fig. 2).

Such gigantic rock barriers and vertical walls are rare in the history of hydro-power construction. Questions that were often asked pertain to the stability of the vertical walls and the rock barriers after excavation. If they were safe and stable at the time of excavation, would their long-term deformation affect the normal operation of the shiplocks and the shiplift? If they were unstable, should the rock barriers be excavated and replaced by reinforced concrete barriers or kept in place but reinforced to maintain their safety? If reinforcement were feasible, what would be the optimum design 
Fig. 3. Displacement monitoring profile $20-20$ of the permanent shiplock slope.

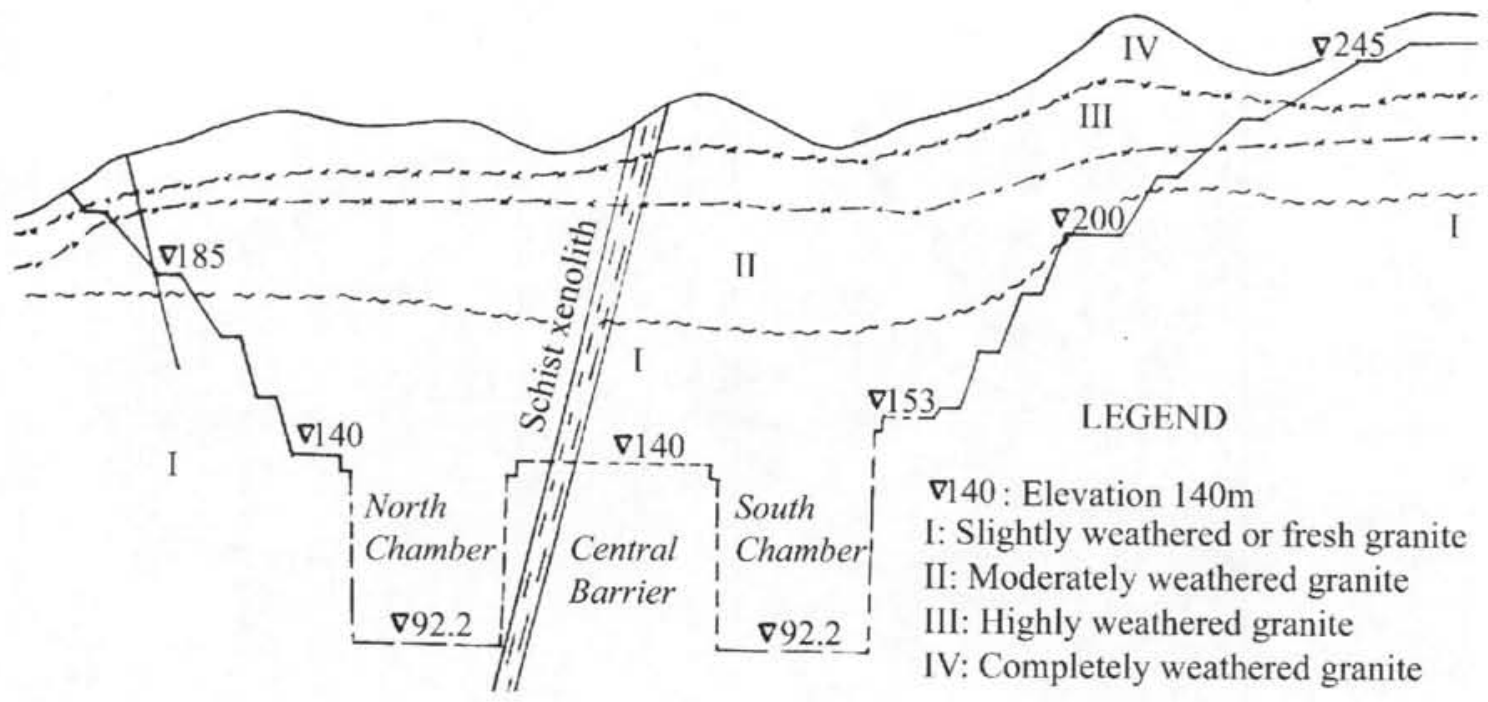

and parameters, and so on? To answer these questions, many studies were conducted during the design stage. Most of the questions were satisfactorily answered. However, two conflicting opinions existed regarding the deformation. Some researchers believed that the deformation would be just several centimetres, the same magnitude as that calculated by the elastic finite element method, but other researchers believed that it could be much larger than the calculated value. The key to answering this question lies in understanding the change in rock-mass properties due to excavation disturbance and in evaluating the mechanical properties of the disturbed zones.

Comprehensive investigations were conducted to determine the actual extent and mechanical properties of the disturbed zone, as summarized in this paper. First, in situ investigations, such as geological and geophysical surveying and borehole elastic modulus testing, were carried out in the central rock barrier between the shiplift and the temporary shiplock. Second, displacements were monitored for the permanent shiplock slope using the sliding deformeter. Third, the extent, mechanical properties, and deformation mechanism of the disturbed zones were defined based on the in situ investigations. Fourth, the disturbed zone was compared with both the tensile stress zones and the shear-damaged zones calculated by the finite element method. Lastly, a reinforcement scheme was recommended.

\section{In situ investigations}

\section{Geological investigation}

The surface topography of the shiplift area generally inclines from northeast to southwest, and most mountain ridges have a north-northeast strike (or nearly north-south) with elevations ranging from 85 to $180 \mathrm{~m}$ and slopes of $15-$ $25^{\circ}$ in general. Bedrock is plagioclase granite with intrusive veins of pegmatite, granite, diabase, and lamprophyre. Four weathered zones are identified, viz. completely weathered (IV), highly weathered (III), moderately weathered (II), and slightly weathered and fresh (I). Faults are relatively well developed. Seventeen faults were mapped in the shiplift area and can be divided into three sets, north-northwest (F23, etc.), north-northeast, and northeast-north-northeast (F548, F603, and F215). The major faults are illustrated in Fig. 4.

The central rock barrier consists of fairly intact fresh granite with no major faults passing through. An area $60 \mathrm{~m}$ long on the top of the barrier and the two vertical walls was selected for detailed geological investigation. Altogether 168 joints of more than $4 \mathrm{~m}$ long were mapped. Joint surfaces were found to be generally smooth or slightly rough (joint roughness coefficient $($ JRC $)=2.5-5.5$ ). Some $64.9 \%$ of the joints were filled, mainly with epidote $(48.2 \%)$ and calcareous minerals $(10.7 \%)$, whereas the others had no infillings. Joints were usually closed or slightly open (with separation $<1 \mathrm{~mm}$ ). However, those exposed at the top of the vertical walls were $1-3 \mathrm{~mm}$ wide, with a few up to $3 \mathrm{~cm}$ wide. The joints could be divided into two groups according to their dip angles (Fig. 5). The first group comprised 151 joints (constituting $91.6 \%$ of the total), dipping at an angle of more than $30^{\circ}$, and could be further subdivided into two major sets, $255^{\circ} / 66^{\circ}$ (strike/dip) and $330^{\circ} / 76^{\circ}$, respectively. The second group comprised only 17 joints, striking at $110-120^{\circ}$ and with dip angles of less than or equal to $30^{\circ}$. Joints were generally persistent. The trace lengths were usually $5-15 \mathrm{~m}$ for the first group and $10-20 \mathrm{~m}$ for the second group. The longest trace length was $32.4 \mathrm{~m}$. The longitudinal axis of the barrier strikes at $119.5^{\circ}$, with most of the joints cutting the barrier at a high angle. Only 37 joints cut the longitudinal axis of the barrier at an angle of less than $30^{\circ}$. Field observation of these unfavourably oriented joints indicated that they could only lead to local wedge slides of very small volumes. The rock barrier was generally stable.

Four vertical boreholes were drilled on the selected profile 3-3 (Fig. 2) for in situ tests, such as sonic logging, crosshole seismic wave penetration, borehole elastic modulus, electromagnetic tomography, and joint mapping inside the rock barrier. Altogether, 133 joints were mapped in the four boreholes by borehole television camera (BTV) and their statistics are shown in Fig. 6. There is some difference between Fig. 5 and Fig. 6, which can be explained by the trace length of the joints. In Fig. 5 only joints with a trace length 
Fig. 4. Three-dimensional schematic view of the major faults in the shiplift area (Chen et al. 1997). Elevations (EL.) in metres.

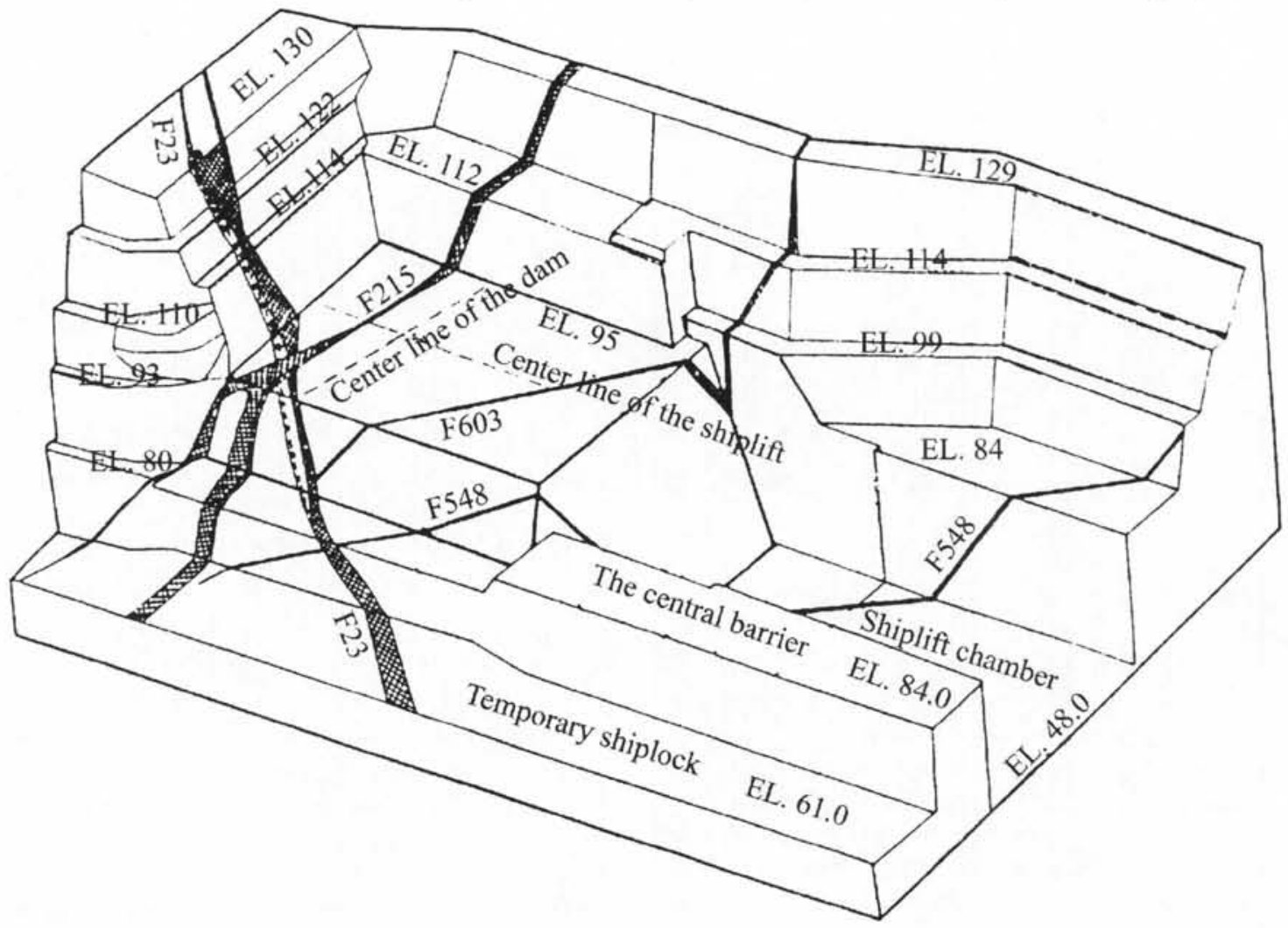

Fig. 5. Pole density contour plot of the surface joints mapped.

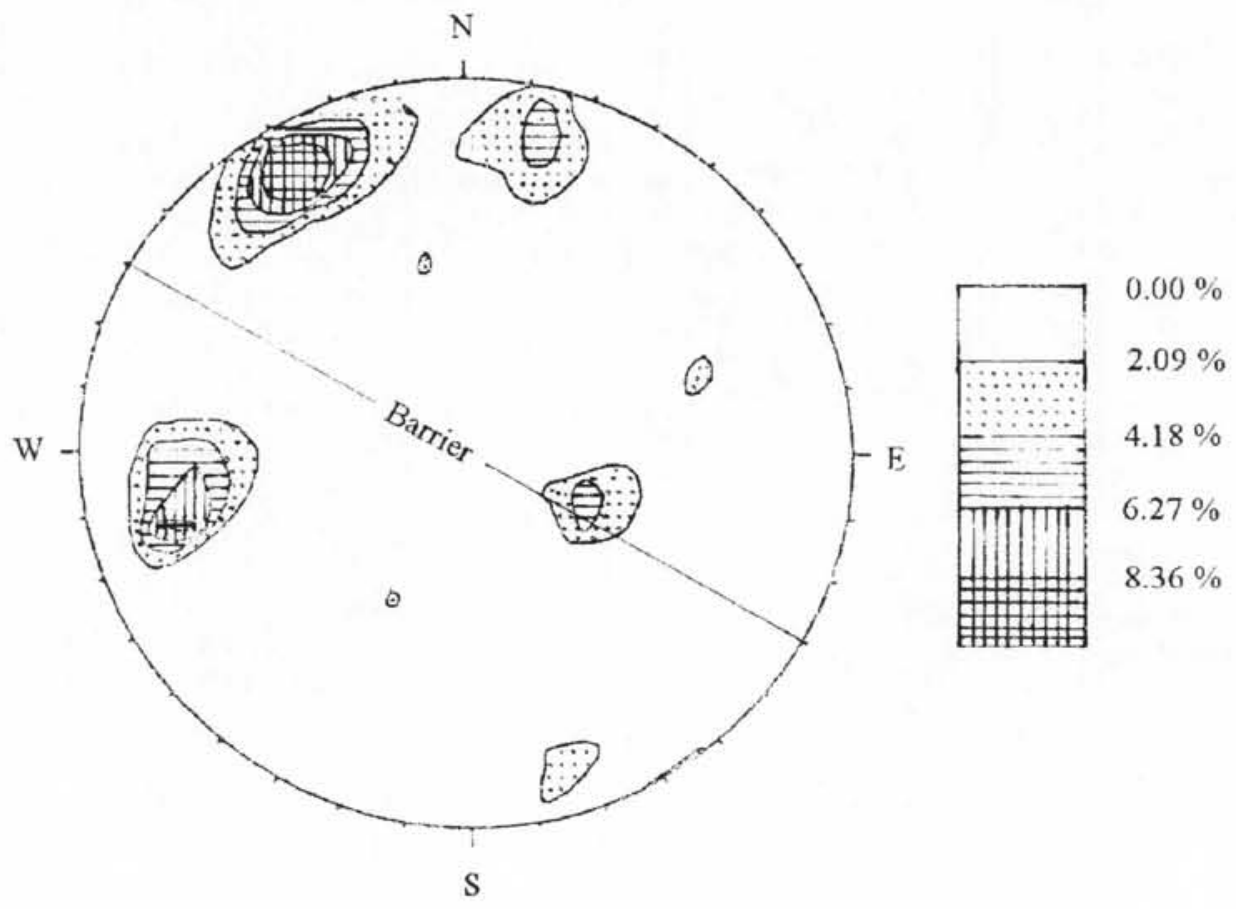

of more than $4 \mathrm{~m}$ were taken into account, whereas in Fig. 6 the trace length was not considered. The mean vertical spacing of joints was in the range of $0.77-1.0 \mathrm{~m}$. Most of the joints were closed, with the number of the open joints decreasing with an increase in borehole depth.
The geology of the test profile is shown in Fig. 7 .

\section{Geophysical surveys}

Geophysical methods were used to investigate the physical behavior of both the rock material and the rock mass in 
Fig. 6. Pole density contour plot of the joints in the four boreholes.

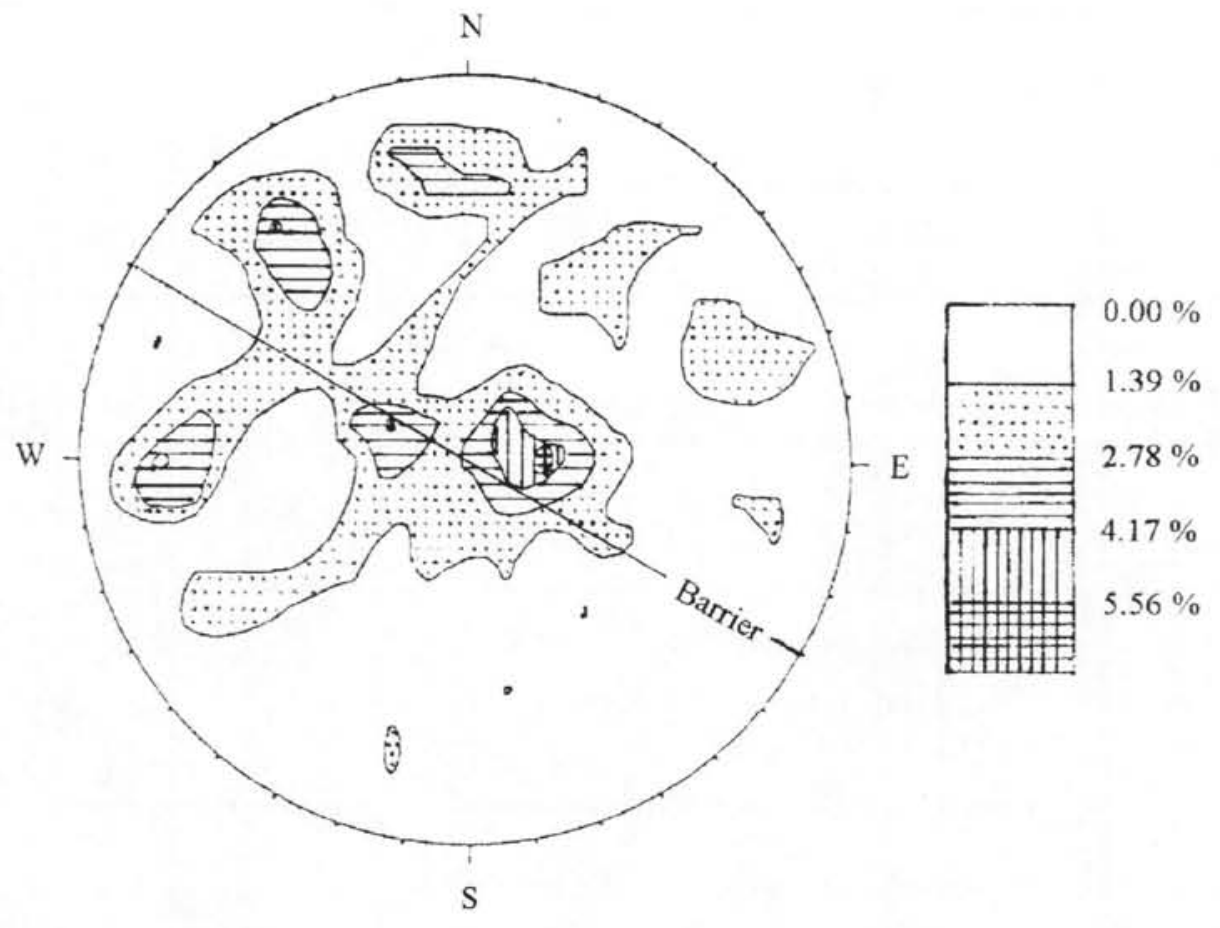

Fig. 7. Geology of the investigation profile.

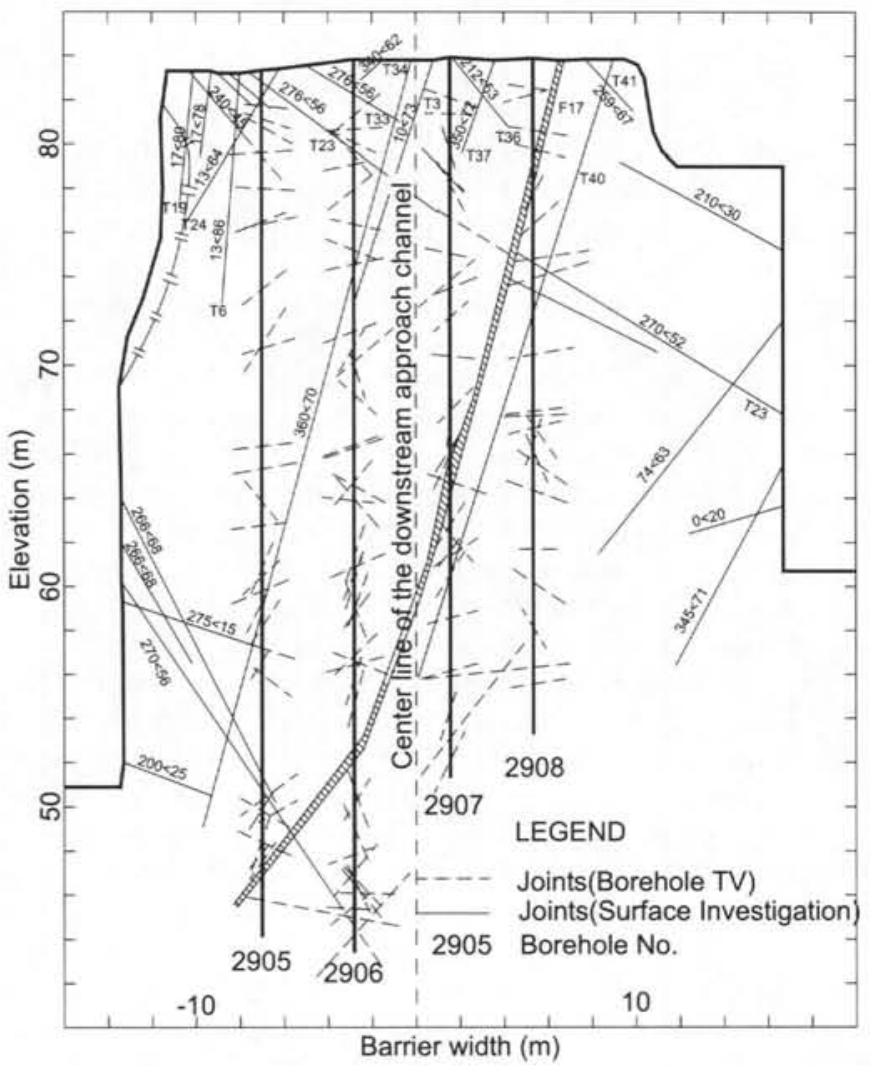

the barrier. Twenty-seven standard specimens $(50 \mathrm{~mm}$ in diameter $\times 100 \mathrm{~mm}$ in length), prepared from core samples at different depths in the four boreholes, were tested for $P$-wave velocity distribution, as shown in Fig. 8 . Two peaks
Fig. 8. Statistical characteristics of $P$-wave velocity of rock specimens.

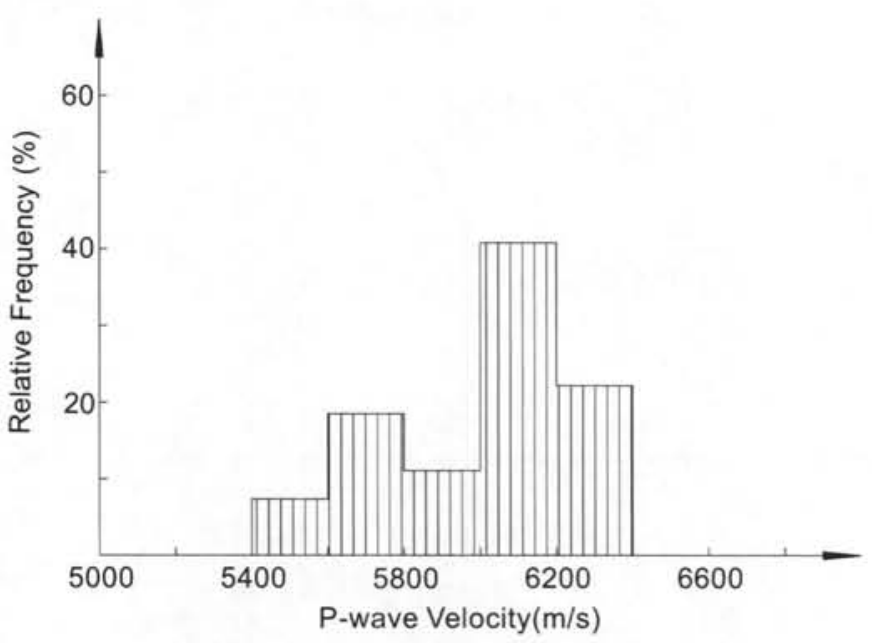

were identified at $6000-6200$ and $5600-5800 \mathrm{~m} / \mathrm{s}$. Nine specimens were further tested for uniaxial strength and elastic modulus. The test data are presented in Table 1 for the nine specimens.

Sonic logging was conducted in the four vertical boreholes at a spacing of one test point every $20 \mathrm{~cm}$. The probe used had one source and two receivers, and the spacing between the two receivers was $20 \mathrm{~cm}$, which was the distance used for the calculation of $P$-wave velocity. Statistical characteristics of the $P$-wave velocities in the four boreholes are shown in Fig. 9 and Table 2. The relationship between velocity and borehole depth is illustrated in Fig. 10. The $P$ wave velocity from sonic logging generally lies between 5500 and $6000 \mathrm{~m} / \mathrm{s}$, but was much lower at the collar of borehole 2905 because it was located in a highly jointed 
Table 1. Test data from rock specimens 1-9.

\begin{tabular}{|c|c|c|c|c|c|c|c|c|c|}
\hline & 1 & 2 & 3 & 4 & 5 & 6 & 7 & 8 & 9 \\
\hline$P$-wave velocity $(\mathrm{m} / \mathrm{s})$ & 5310 & 5530 & 5930 & 5670 & 5660 & 5950 & 6170 & 5860 & 6010 \\
\hline Uniaxial compressive strength (MPa) & 101 & 166 & 139 & 121 & 157 & 153 & 75 & 110 & 84 \\
\hline Elastic modulus (GPa) & 38 & 66 & 58 & 53 & 61 & 60 & 38 & 50 & 38 \\
\hline
\end{tabular}

Table 2. $P$-wave velocity statistics from sonic logging and seismic wave penetration tests.

\begin{tabular}{lllll}
\hline & Maximum & Minimum & Average & Range \\
\hline Sonic logging & 6060 & 2860 & 5610 & $5500-6000$ \\
Seismic wave penetration & 5986 & 2100 & 4300 & $3000-3500,4000-5500$ \\
\hline
\end{tabular}

Table 3. $P$-wave velocity statistics from seismic wave penetration tests conducted between boreholes 2905 and 2906,2906 and 2907 , and 2907 and 2908.

\begin{tabular}{|c|c|c|c|c|}
\hline & 2905-2906 & $2906-2907$ & $2907-2908$ & Mean \\
\hline Elevation of the inflection point (m) & 68 & 74 & 67 & \\
\hline Mean $P$-wave velocity above the inflection point $(\mathrm{m} / \mathrm{s})$ & 3166 & 3479 & 3095 & 3206 \\
\hline Mean $P$-wave velocity below the inflection point $(\mathrm{m} / \mathrm{s})$ & 4782 & 5245 & 4950 & 4997 \\
\hline Decrease in $P$-wave velocity $(\%)$ & 33.8 & 33.7 & 37.5 & 35.8 \\
\hline
\end{tabular}

Fig. 9. Statistical characteristics of $P$-wave velocity from sonic logging and cross-hole seismic wave penetration tests.

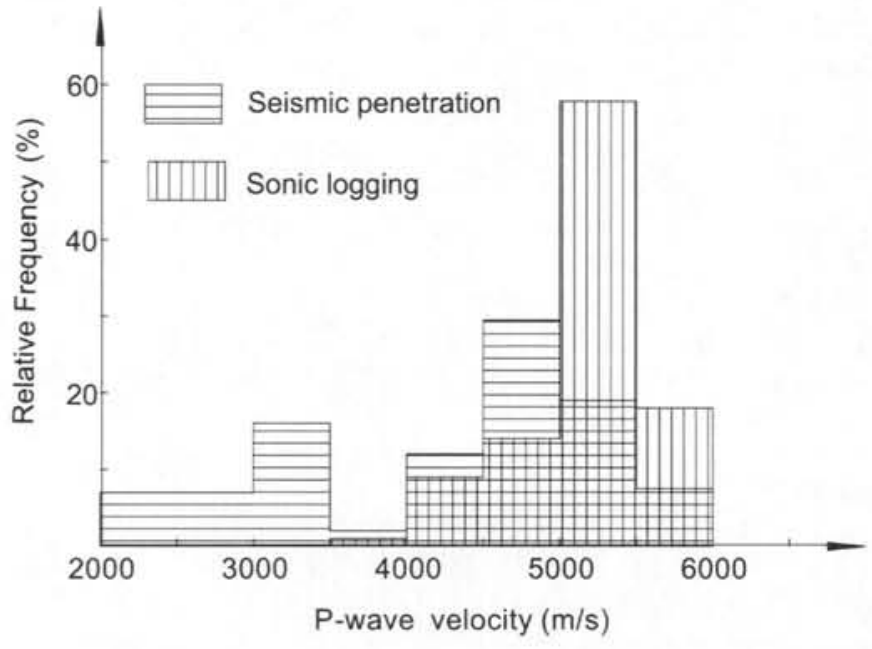

zone. Water leakage was serious in the upper parts of the boreholes and the water table could not be maintained, even with continuous pumping. Hence, the velocity determination could not be completed for both the sonic logging and the seismic wave penetration testing.

Seismic wave penetration testing was conducted between boreholes 2905 and 2906, 2906 and 2907, and 2907 and 2908. Sources were triggered by detonators at a spacing of $1 \mathrm{~m}$ along the borehole depth. The receiver was at the same elevation as the source, and the horizontal distance between the holes was assumed to be traversed by $P$ waves. The statistical characteristics of $P$-wave velocity distribution are illustrated in Fig. 9 and Table 2. There are two velocity concentrations, namely $3000-3500$ and $4000-5500 \mathrm{~m} / \mathrm{s}$. The relationship between wave velocity and borehole depth is shown in Fig. 10. The test points in the upper part of the barrier have lower velocities in the range $3000-3500 \mathrm{~m} / \mathrm{s}$, and those in the lower part of the barrier have higher velocities in the range $5000-5500 \mathrm{~m} / \mathrm{s}$. An inflection point is defined where the velocity decreases rapidly from around 5000 to $3500 \mathrm{~m} / \mathrm{s}$; the mean wave velocities above and below the point are summarized in Table 3 . Local points with a velocity of less than $5000 \mathrm{~m} / \mathrm{s}$ in the lower part of the barrier are discussed later in the paper.

Electromagnetic tomography was used for determining the factor of absorption $\beta$ (NEPR/m) of the rock mass in the barrier. $\beta$ is a parameter used herein for characterizing the rock mass, and NEPR (neper) is a unit on a natural logarithmic scale for expressing the relationship between two amounts of acoustic power, equal to one half of the natural logarithm of the ratio of the two powers compared. In general, higher values mean poorer rock-mass quality, and vice versa. Two sections were tested, with the first one between hole 2906 and the vertical wall on the shiplift side and the second between the holes 2906 and 2908. The section between hole 2908 and the vertical wall on the temporary shiplock side was not tested, as scaffolding for wall reinforcement was set up during the test period. The tomography is shown in Fig. 11. Four higher absorption zones $(\beta>0.15)$ were found. The first zone corresponds to the highly jointed zone at the top of the vertical wall on the left. The other three are correlated to zones either with lower uniaxial compression strength of rock specimens or with lower seismic wave velocity. Out of the four specimens with lower uniaxial compression strength and elastic modulus, one was sampled from zone II (specimen 1 in Table 1 and Fig. 11) and the other three were sampled from zone IV (specimens 7-9). In Fig. 10b, the average $P$-wave velocity is $4762 \mathrm{~m} / \mathrm{s}$ for seismic penetration points between elevations 61 and $67 \mathrm{~m}$, whereas the average velocity is $5804 \mathrm{~m} / \mathrm{s}$ for points below elevation $61 \mathrm{~m}, 1042 \mathrm{~m} / \mathrm{s}$ higher than that between elevations 61 and $67 \mathrm{~m}$. With reference to Fig. 11, the zone between boreholes 2906 and 2907 at an elevation of $61-67 \mathrm{~m}$ coincides with the location of the higher absorption zone III. The low part of section 29052906 (below elevation $61 \mathrm{~m}$ ) is located in the higher absorption 
Fig. 10. $P$-wave velocity characteristics with borehole depth from sonic logging and cross-hole seismic wave penetration tests.
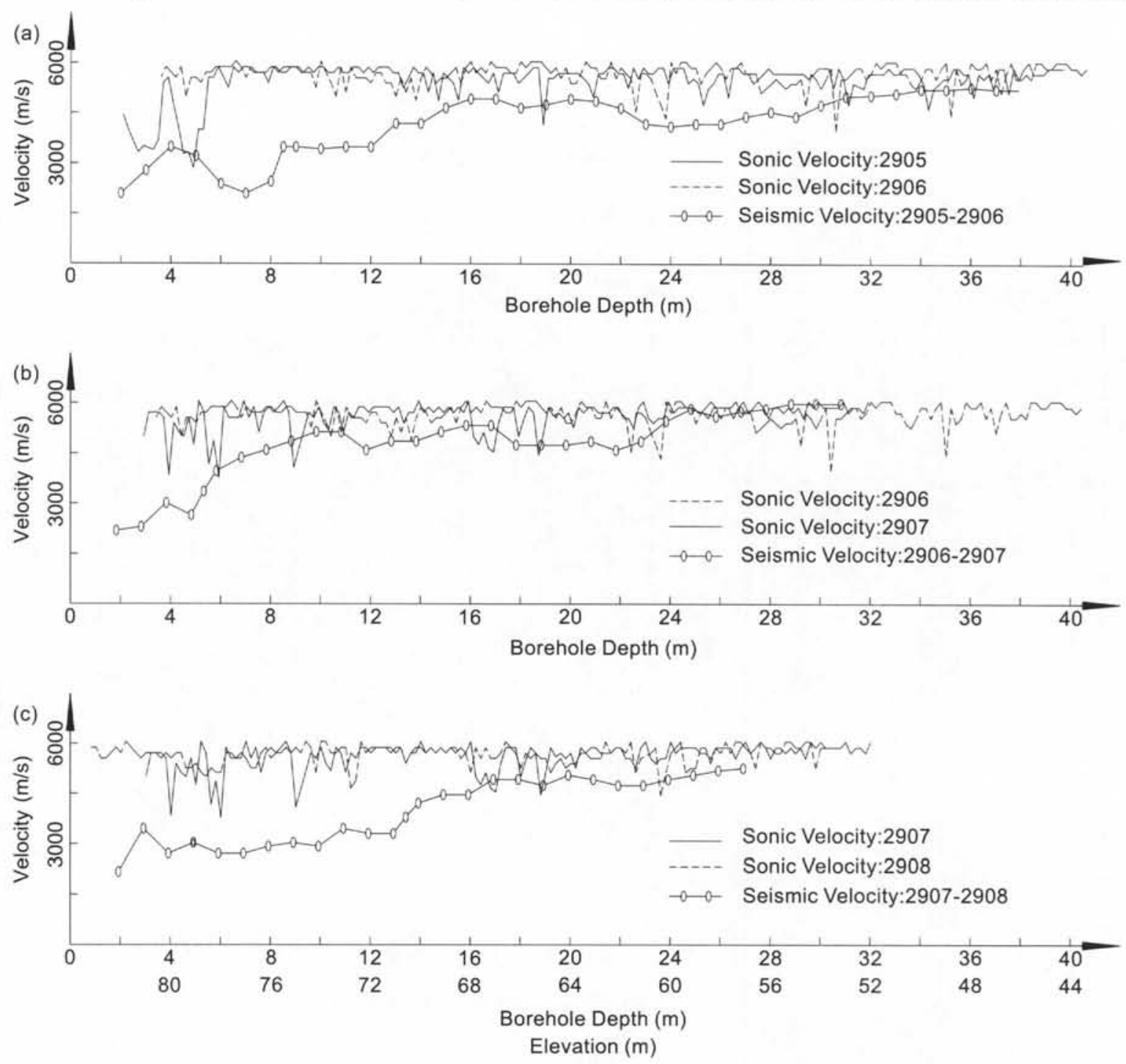

zone IV and its average $P$-wave velocity is $4766 \mathrm{~m} / \mathrm{s}$, also much lower than that for the lower part of section 2906 2907 (5804 m/s). Hence, we conclude that a higher absorption factor means poorer rock quality.

\section{Borehole elastic modulus test}

The improved Goodman jack was used for borehole elastic modulus testing in the four boreholes on the test profile. The loading direction was horizontal on the test profile, perpendicular to the longitudinal direction of the barrier. The objective of the test was to determine if the elastic modulus of the rock mass has undergone any significant change along the axis of the hole after destressing of the rock mass due to excavation. The modulus values are more easily affected by local structures at the test points. Figure 12 shows the test results and the location of local fractures. For borehole 2906 , the two values at the bottom of the hole are likely caused by the presence of local fractures, whereas those at the bottom of hole 2907 are likely caused by poorer rock quality in zone IV. Although some lower values in the upper part of the barrier may be caused by the presence of local fractures, it is obvious that the values in the upper part of the barrier are generally lower than those in the lower part. Therefore, inflection points are defined where the modulus values decrease rapidly. The elevations of the inflection points and the average modulus values above and below them are listed in Table 4.

\section{Properties of the disturbed zone}

The peak $P$-wave velocities for the rock specimens are $6000-6200 \mathrm{~m} / \mathrm{s}$, and the background values from sonic logging are $5500-6000 \mathrm{~m} / \mathrm{s}$, giving a difference of only about $500 \mathrm{~m} / \mathrm{s}$. The spacing between the source and the receiver is $10 \mathrm{~cm}$ for a rock specimen and $20 \mathrm{~cm}$ for borehole sonic logging, values which are much smaller than the mean vertical spacing of joints $(77-110 \mathrm{~cm})$. If we further consider the fact that $P$-waves take more time to traverse water during sonic logging, then this difference is small and the background value could be considered as the velocity of the rock specimens.

Figure 10 illustrates that there is no major change in $P$ wave velocity along the borehole depth, which implies that the mechanical properties of rock blocks were essentially unchanged by the excavation. Most of the joints revealed by 
Fig. 11. Electromagnetic tomography of the test profile. Contours represent the factor of absorption $\beta$, with a contour interval of 0.05 .

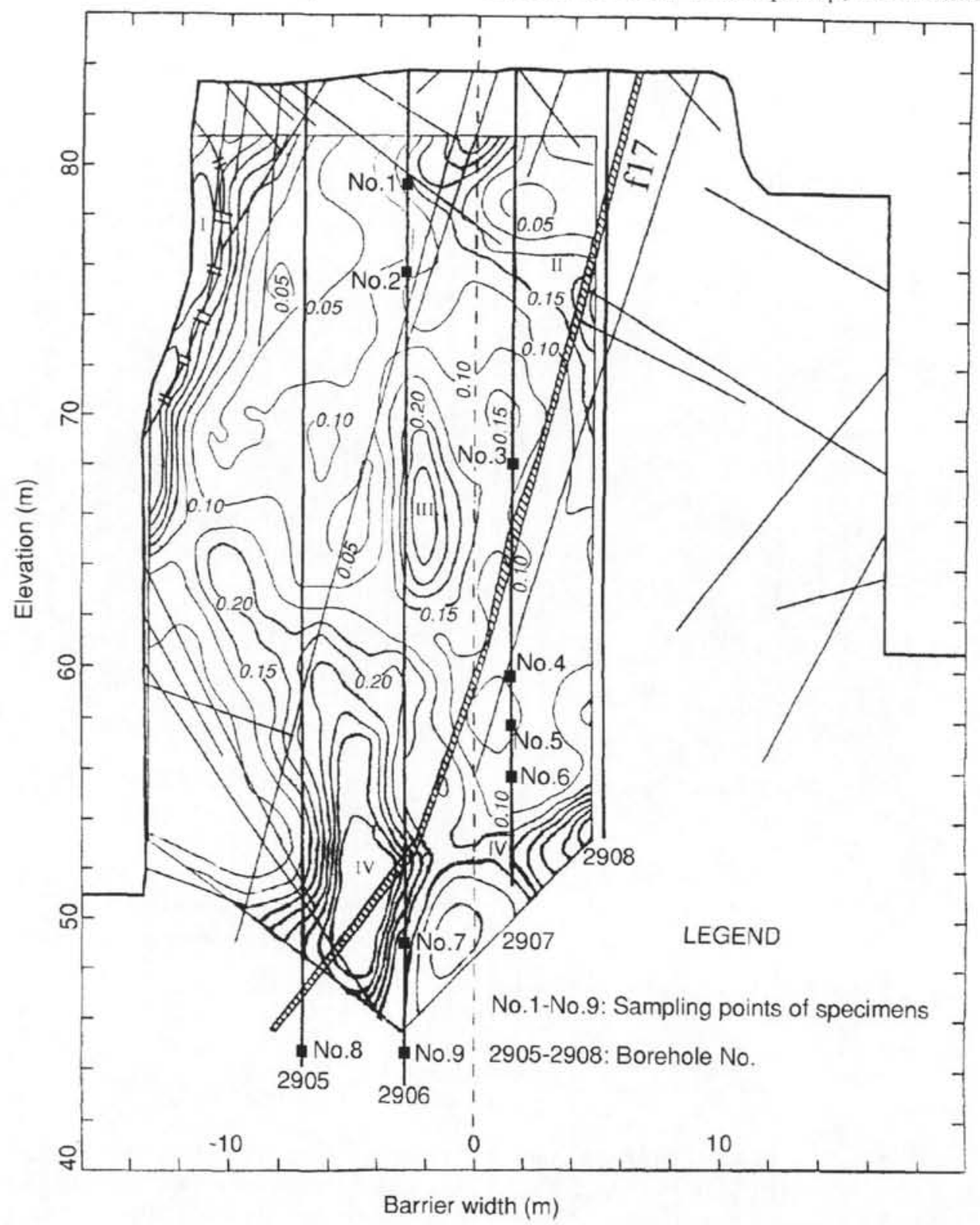

Table 4. Elastic modulus statistics for boreholes 2905-2908.

\begin{tabular}{lllll}
\hline & 2905 & 2906 & 2907 & 2908 \\
\hline Elevation of the inflection point $(\mathrm{m})$ & 65 & 68 & 71 & 67 \\
Mean elastic modulus above the inflection point $(\mathrm{GPa})$ & 23.5 & 32.5 & 33.0 & 29.8 \\
Mean elastic modulus below the inflection point $(\mathrm{GPa})$ & 37.1 & 37.0 & 37.3 & 37.8 \\
Decrease in elastic modulus $(\%)$ & 31.3 & 12.3 & 11.5 & 21.0 \\
\hline
\end{tabular}

the core and BTV investigations were old. The few fresh joint planes were in planar form, slightly rough, and dipping at a high angle. Hence they were likely to have resulted from the opening of closed, primary structural planes under the disturbance of excavation or coring.

The mechanical properties of the rock blocks were essentially unchanged after excavation. No newly formed struc- tural planes were found inside the rock barrier. From the electromagnetic tomography, the quality of the rock mass in the upper part of the rock barrier appears to be better than that in the lower part. The question that can be asked is then the following: what brings about the sharp decrease of both seismic velocities and elastic modulus in the upper part of the rock barrier? In the opinion of the authors, the only 
Fig. 12. Elastic modulus versus borehole depth.
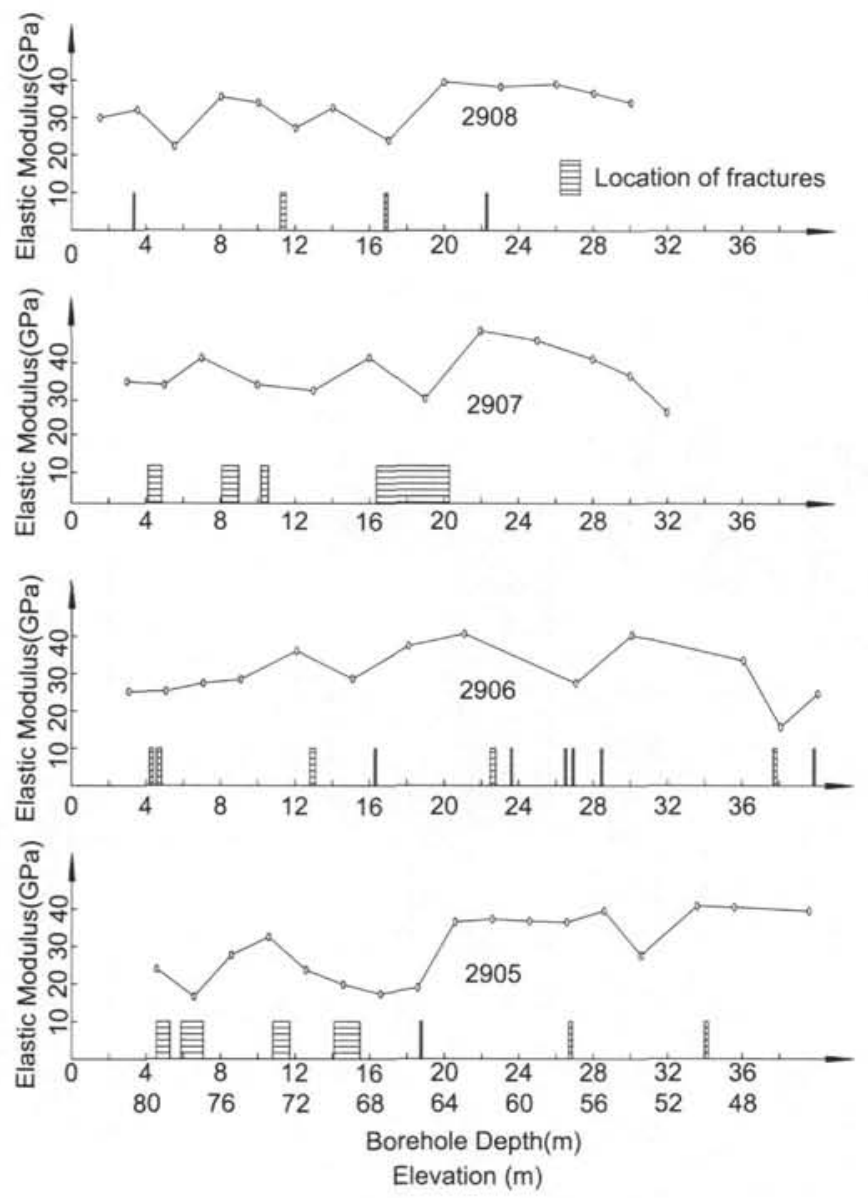

reasonable explanation is the opening of the primary structural planes or the aperture extension that resulted from local sliding deformation on the primary structural planes.

The boundary between the disturbed and undisturbed zones in the central rock barrier is determined by the inflection points of the curves of $P$-wave velocity from both seismic wave penetration and borehole elastic modulus testing. The scope of the disturbed zone is shown in Fig. 13, in which the broken line is inferred and will be further discussed in the next section.

\section{Displacement monitoring}

\section{Displacements monitored by sliding deformeter}

In Fig. 13, the horizontal extent of the disturbed zone is inferred. Sonic logging was used in horizontal bolt reinforcement holes to determine the horizontal extent of the zone, but the results were not satisfactory, in part because water leakage was more serious in the horizontal holes, but mainly because of the inherent limitation of the test method. Sonic logging is an effective method for detecting the existence of local fractures; however, the central barrier consisted of fairly intact fresh granite and the spacing of fractures was much greater than $20 \mathrm{~cm}$ (which was the spacing between the two receivers). Hence, sonic logging data could mainly reflect the $P$-wave velocity of intact granite only. For determination of the extent of the disturbed zone, it
Fig. 13. Disturbed zone in the central barrier.

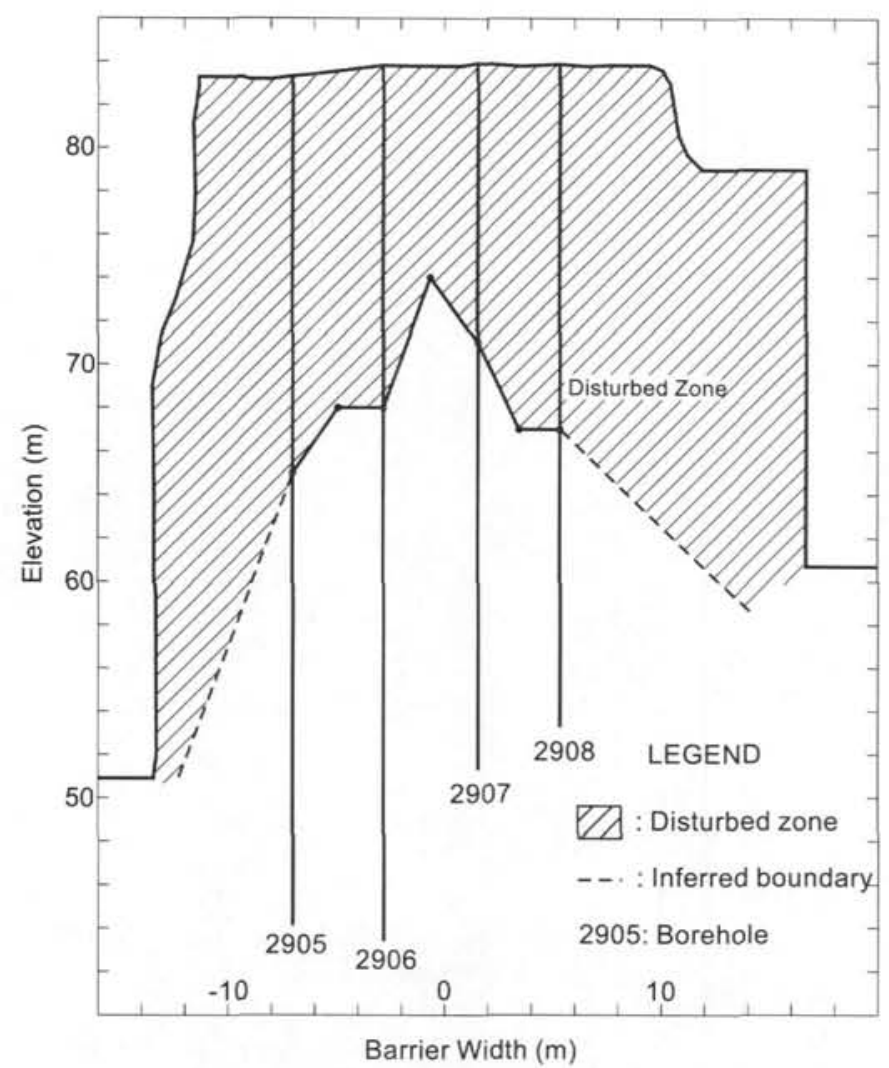

would be necessary to measure parameters that could directly or indirectly reflect the opening of the primary structure planes.

The dilation characteristics of the rock mass could be used for determining the horizontal extent of the disturbed zones. On the Three Gorges Project, the horizontal deformation inside the rock mass was mainly monitored using multiplepoint borehole extensometers, which were installed between the vertical walls and the drainage tunnels. Extensometers could provide only limited deformation data, usually six values in one hole, which would be insufficient to depict the deformation characteristics of the rock mass. Therefore we used the sliding deformeter to provide the additional data. Five horizontal boreholes were drilled in the north slope of the permanent shiplock. Figure 14 shows the layout of the monitoring boreholes along profile 20-20. The distance between the borehole bottom and the vertical wall is $4 \mathrm{~m}$. The monitored data are presented herein in two ways, namely the measured point displacement versus borehole depth and the cumulative displacements versus borehole depth. The base point was selected at the collar of the borehole. The cumulative displacements of the two boreholes over a half-year period are also shown in the figure. The portion of the rock mass immediately next to the vertical wall deformed significantly, demonstrating a sharp increase in the curve of cumulative displacement versus borehole depth. We refer to this region as the disturbed zone. The zone near the drainage tunnel underwent little deformation (except for deformation due to tunnelling) and was thus termed the undisturbed zone. There existed a large transition zone between the undisturbed and disturbed zones. The transition zone was not as 
Fig. 14. Layout of the monitoring boreholes in profile 20-20. Elevations in metres.

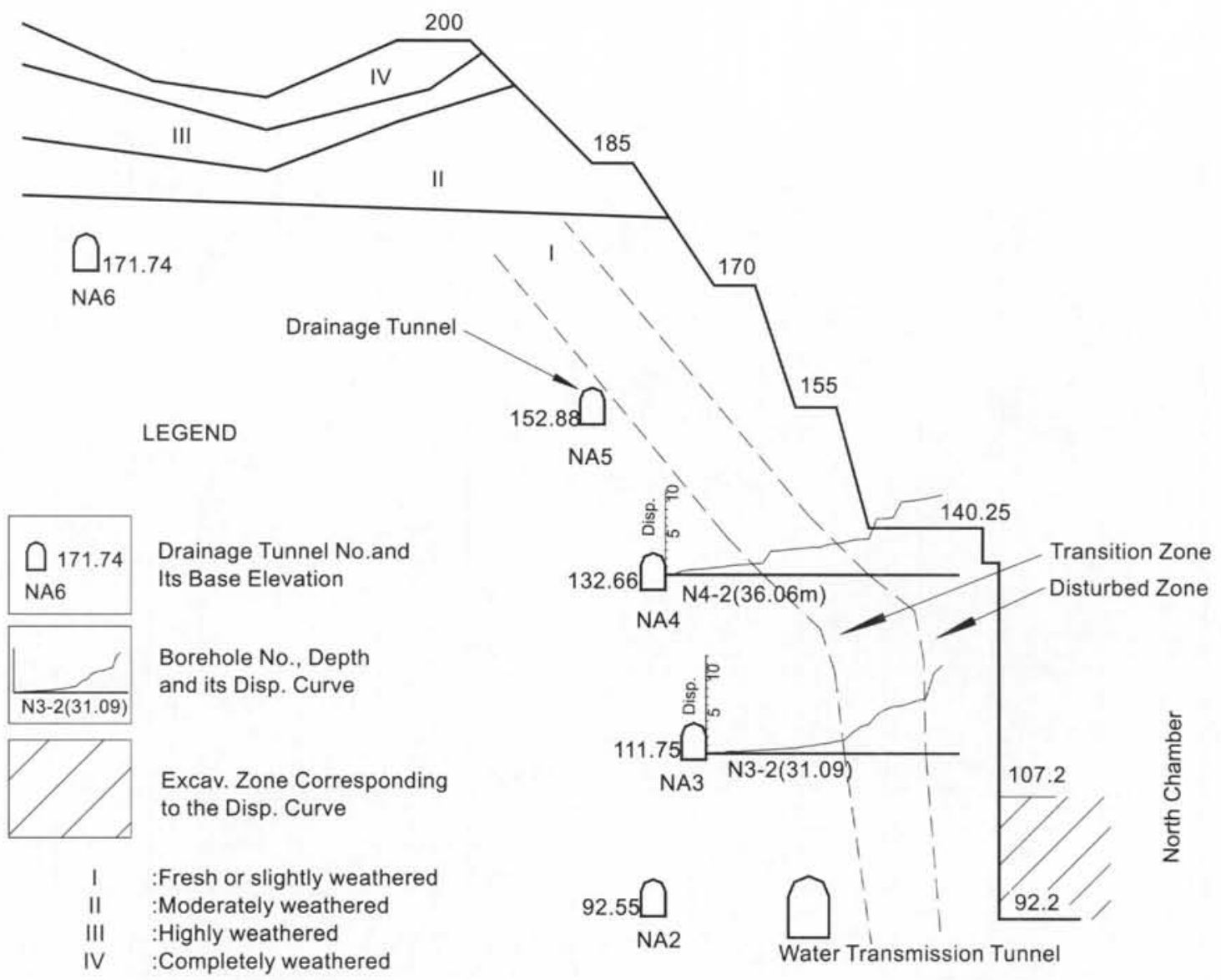

Fig. 15. Point-wise horizontal displacement versus borehole depth.

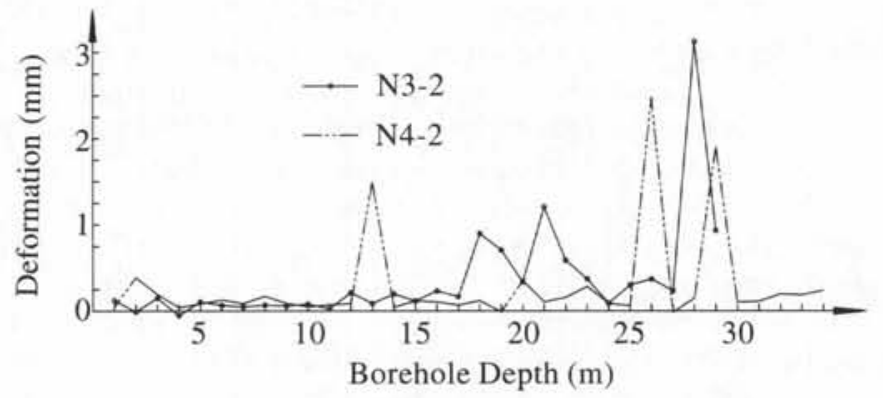

apparent in Figs. 10 and 12 as in Fig. 14. This difference could have resulted from the test methods used and the local geological conditions.

\section{Deformation mechanism of the rock masses}

From the test results in the rock barrier between the shiplift and the temporary shiplock, we have concluded that the reduction in rock quality in the disturbed rock mass was caused by the opening of primary structural planes or by the sliding of local rock blocks along primary structural planes. This conclusion could be further verified by the results of displacement monitoring. Figure 15 shows the curves of the point-wise horizontal deformation versus borehole depth for holes N3-2 and N4-2. The point-wise deformation was mainly composed of displacements measured at depths of $18,19,21,28$, and $29 \mathrm{~m}$ for hole N3-2 and 13, 26, and $29 \mathrm{~m}$ for hole N4-2. Points with large deformation were located in heavily jointed zones. For example, the rock quality designation (RQD) was 64\% around a depth of $29 \mathrm{~m}$ and $0 \%$ around a depth of $19 \mathrm{~m}$, whereas it was usually not less than $94 \%$ in the other sections of N3-2.

Displacement measurements of typical points in test holes N3-2 and N4-2 are summarized in Table 5.

\section{Reinforcement for the disturbed zones}

The principal structural plane sets intersect the central rock barriers and the slopes at the Three Gorges Project site at a high angle and the probability of a large-scale plane or wedge slide is hence low. The rock barriers and slopes are stable, in general, and any need for rock reinforcement would be confined locally to the disturbed zones, especially in disturbed zones of the central rock barriers and the vertical walls, since their stability and deformation could affect the normal operation of the shiplocks or shiplift. Thus the main purpose of reinforcement would be to prevent the local collapse of rock blocks, to control the long-term deformation and stability of rock mass, and to prevent the disturbed zone from being further extended or disturbed.

The primary horizontal stresses are about $8-10 \mathrm{MPa}$ in the areas of the rock barriers and the upper parts of the vertical walls. Three-dimensional (3D) finite element analysis was 
Table 5. Point-wise horizontal displacements for test holes N3-2 and N4-2.

\begin{tabular}{ll}
\hline Point No.* & $\begin{array}{l}\text { Displacement } \\
(\mathrm{mm})\end{array}$ \\
\hline $\mathbf{N 3 - 2}$ & 0.900 \\
18 & 0.709 \\
19 & 1.207 \\
21 & 3.129 \\
28 & 0.936 \\
29 & 6.881 \\
Total & \\
N4-2 & 1.497 \\
13 & 2.484 \\
26 & 1.904 \\
29 & 5.885 \\
Total & \\
\hline * Indicates depth $(\mathrm{m})$ in the borehole.
\end{tabular}

carried out (Zheng et al. 1997; Deng et al. 1998, 1999) for the barrier and the slopes of the shiplift and the temporary shiplock. Three constitutive stress-strain relations, namely linear elastic (E), elasto-plastic (EP), and elasto-brittleplastic (EBP), were used in the analysis. After excavation, both the rock barriers and the upper parts of the vertical walls were found to be in a low stress state with horizontal stresses of no more than $1 \mathrm{MPa}$ remaining, according to the results of the 3D finite element analysis. There were local tension zones with horizontal tensile stresses of around $1 \mathrm{MPa}$. Shear-damaged zones and tensile stress zones thus predicted by computer modelling were compared with the measured disturbed zone as shown in Figs. 16 and 17 for the rock barrier. Destressing was one of the main reasons for the formation of the disturbed zone; and other reasons included blast damage. Drilling and blasting was the main excavation method employed on this project and its contribution to the formation of the disturbed zone can be divided into two aspects, namely direct fracturing of the rock blocks near the surface and acceleration of the destressing process and formation of the disturbed zone through seismic waves. Hence, on the Three Gorges Project the first step to stabilize the rock slope would be to control the extent of the disturbed zone through the use of controlled blasting techniques.

The mechanical properties of the rock blocks were basically unchanged and there were no newly formed structural planes inside the disturbed zones. Thus the basic effect of reinforcement was to keep the rock blocks together, enhance the integrity of the rock mass, and prevent the extent and deformation of the disturbed zone from developing further.

For the reinforcement of the vertical walls, the anchor part of the rock bolt should lie in the undisturbed rock mass. Based on in situ investigation of the extent of the disturbed zone, the bolts should be significantly longer than $20 \mathrm{~m}$, which would be too long for bolt anchoring. Hence, on the Three Gorges Project, a combined anchoring scheme of cable bolts and rock bolts was used. Cable bolts of $3000 \mathrm{kN}$ capacity were installed as the main reinforcing means at $3 \mathrm{~m}$ horizontal spacing between drainage tunnels NA3, NA4, $\mathrm{SA} 3$, and SA4 and the vertical walls (Fig. 14). Partly grouted bolts, 6-18 m long and anchored in the transition zone, were then installed between two rows (upper and
Fig. 16. Comparison between the observed disturbed zone and the calculated tensile stress zones for elastic (E), elasto-plastic (EP), and elasto-brittle-plastic (EBP) cases.
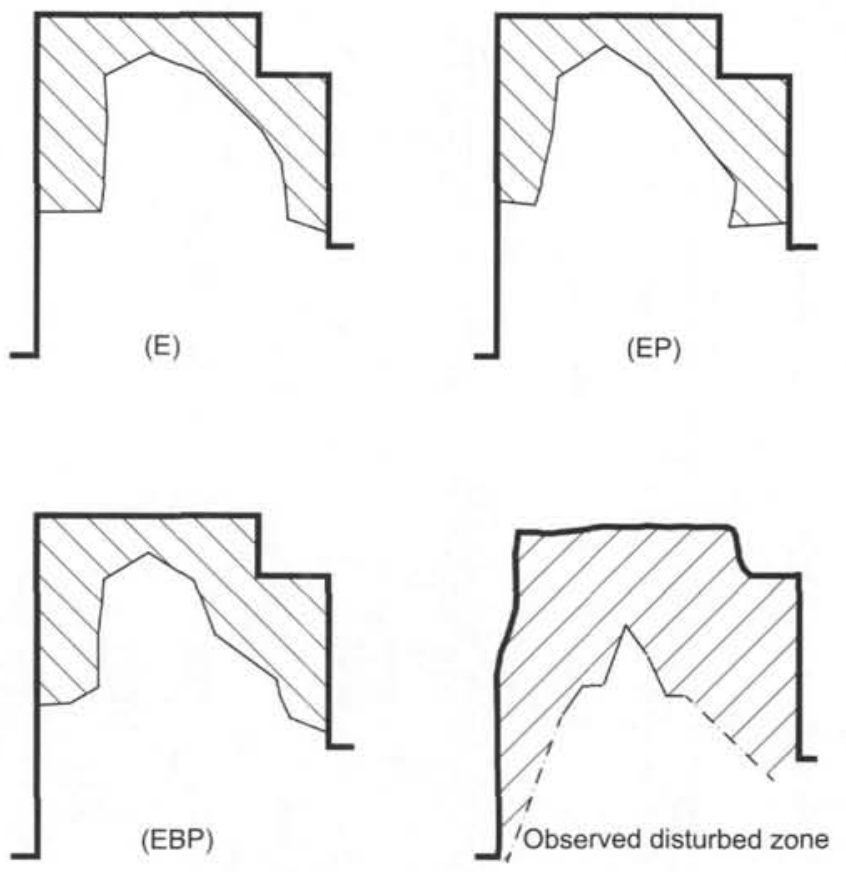

lower rows) of cable bolts as a supplementary means of tackling local unstable blocks. For the rock barriers, as the upper parts were highly disturbed, there was no undisturbed rock mass for anchorage purposes. Two rows of cable bolts were installed to interlock the upper part of the disturbed rock mass between the two vertical walls. In the lower part, partly grouted bolts were used. Shotcrete was applied to the surface of both the rock barriers and the slopes for the prevention of rockfalls and rainfall infiltration.

Comparing Figs. 16 and 17, the calculated tensile stress zones and shear-damaged zones, as obtained from 3D finite element analysis, are similar to the observed disturbed zones in both shape and extent. They could therefore be used as reference in the design and layout of reinforcement.

\section{Conclusions}

After excavation, a relatively weak zone of rock would be formed underneath the excavation surface because of destressing, blast damage, etc. This zone is herein referred to as the disturbed zone. In this paper, methods for the determination of the disturbed zone are discussed. Mechanical properties of the disturbed zone are analyzed based on field investigations in the central rock barriers and steep slopes at the Three Gorges Project site. The main results are summarized as follows:

(1) The vertical extent of the disturbed zone can be determined by cross-hole seismic penetration test or borehole elastic modulus test if the principal structural planes dip at a high angle and the destressing direction is mainly horizontal. For the horizontal extent, the deformation characteristics of the rock mass can be used. These characteristics could be monitored by linear instruments such as micrometers or sliding deformeters. 
Fig. 17. Comparison between the observed disturbed zone and the calculated shear-damaged zones for elastic (E), elasto-plastic (EP), and elasto-brittle-plastic (EBP) cases.
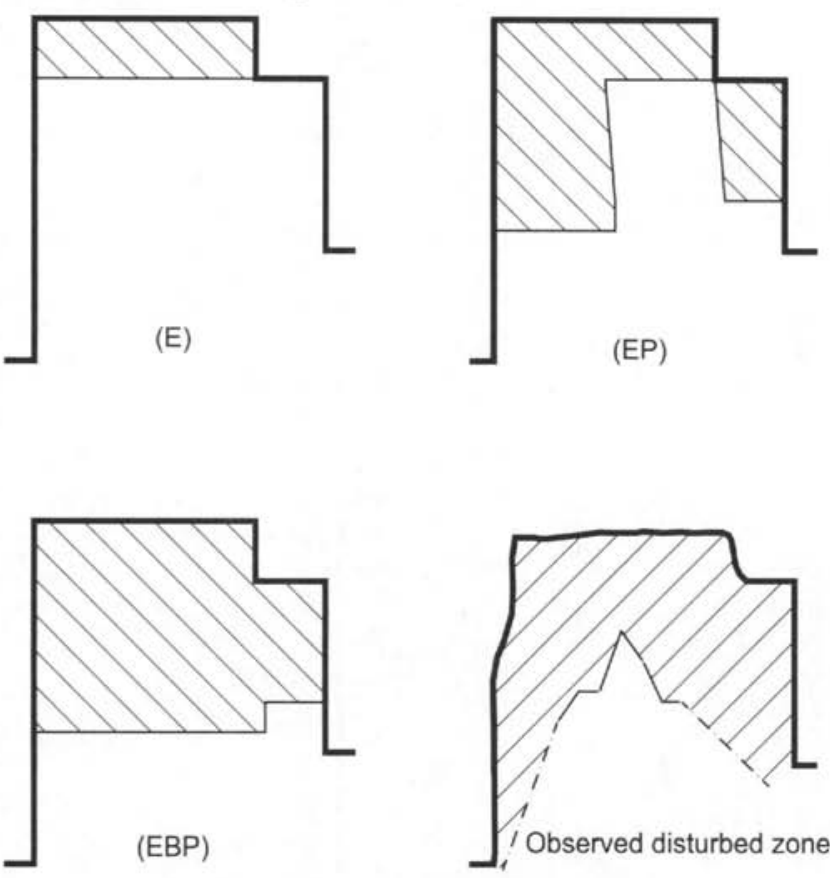

(2) A disturbed zone in the shape on an inverted $U$ was detected in the middle and upper parts of the central rock barrier between the shiplift and the temporary shiplock. From deformation measurements, a transition zone was found between the disturbed zone and the confined rock mass in the north slope of the permanent shiplock; however, the transition zone was not apparent in the velocity characteristics obtained from seismic tests.

(3) The rock mass in the disturbed zone exhibited tension and local sliding of blocks along the primary structural planes, thereby becoming poorer in rock quality. Otherwise, the mechanical properties of the rock blocks were basically unchanged.

(4) Rock-mass behavior after excavation would be governed by the disturbed zone. The primary structural planes were the inherent cause for the formation of the disturbed zone. Hence for stability evaluation and control of deep excavations and cut slopes in rock, a good knowledge of the structural planes and the disturbed zones is essential.

(5) On the Three Gorges Project, the principal structural planes intersect the longitudinal axis of the slopes and barriers at a high angle. Hence the probability of plane or wedge slides would be very low, and the rock barriers and slopes would be in a stable state generally.

(6) For the reinforcement of the disturbed zone, presentation of the rock mass assembly is important. Whether cable bolts or conventional rock bolts are used, the anchorage should be located in the confined or relatively undisturbed rock mass.

(7) Validated by field observations, the results of the $3 \mathrm{D}$ finite element analysis could be used as a reference in the design and layout of rock reinforcement.

\section{Acknowledgements}

The China Three Gorges Project Development Corporation (CTGPC) provided generous financial support for the study. Funding was also partially provided by the China Natural Science Foundation, Item B40 on the list of national key projects of basic and applied research (mounting plan). Part of the work in this paper was the product of a collaborative research project of the Institute of Rock and Soil Mechanics, Chinese Academy of Sciences, the Changjiang Water Resources Committee, and the University of Hong Kong. The authors would like to thank all their colleagues who have made contributions to part of the work described here, including Professors Cheng Kunhuang, Xiu Linxiang, Xue Guofu, Yang Qigui, Zheng Hong, and Sheng Qian, Mr. Liu Fangwen, Mr. Wang Hao, and others.

\section{References}

Chen, D.J., Xue, G.F., Xiu, F.X., et al. 1997. Engineering geology research of the Three Gorges Project. Hubei Science and Technology Press, Wuhan, China.

Deng, J.H., Chen, W.S., Zheng, H., et al. 1998. 3D finite element analysis of the slope of the Three Gorges Project's temporary shiplock and shiplift. In Numerical and Analytical Methods in Geomechanics, Proceedings of the 6th National Conference on Numerical and Analytical Methods in Geomechanics, Guangzhou, 4-6 August. Edited by P.Y. Lu and Y.S. Shi. Guangdong Science and Technology Press, China. pp. 60-65.

Deng, J.H., Ge, X.R., Bai, S.W., et al. 1999. Mechanical properties for the rockmass in the central barrier of temporary shiplock in Three Gorges Project. In Proceedings of the 9th International Congress on Rock Mechanics of the International Society for Rock Mechanics, Paris, 25-28 August. Edited by G. Vouille and P. Berest. A.A. Balkema, Rotterdam, The Netherlands, Vol. 2, pp. $1355-1357$.

Zheng, H., Ge, X.R., and Lee, C.F. 1997. Analysis principle for rockmass with brittle-plasticity and its applications. Chinese Journal of Rock Mechanics and Engineering, 16(1): 8-21. 